\title{
Temperature Measurement of Power Semiconductor Devices by Thermo-Sensitive Electrical Parameters - A Review
}

\author{
Yvan Avenas $^{1}$, Laurent Dupont ${ }^{2}$, Zoubir Khatir ${ }^{2}$ \\ ${ }^{1}$ G2Elab, Université de Grenoble, BP 46, 8302 Saint Martin d'Hères Cedex, France \\ ${ }^{2}$ LTN/IFSTTAR, 25 allée des Marronniers, 78000 Versailles, France
}

\begin{abstract}
This paper proposes a synthesis of different electrical methods used to estimate the temperature of power semi-conductor devices. The following measurement methods are introduced: the voltage under low current levels, the threshold voltage, the voltage under high current levels, the gate-emitter voltage, the saturation current and the switching times. All these methods are then compared in terms of sensitivity, linearity, accuracy, genericity, calibration needs and possibility of characterizing the thermal impedance or the temperature during the operation of the converter. The measurement of thermo-sensitive parameters of wide band gap semi conductors is also discussed.
\end{abstract}

Index Terms - Chip temperature, Power electronics, Semiconductor devices, Thermo-sensitive electrical parameter 


\section{INTRODUCTION}

The temperature measurement of a power semiconductor device is of great interest. This important parameter is used in two main ways. The first one is for thermal management of power modules. In this case, the chip temperature is used to get the thermal resistance or thermal impedance of the component that is usually provided by manufacturers in the data-sheet. The second use concerns the monitoring of the aging of components for reliability reasons. For this purpose, temperature is monitored and used either directly or indirectly through the thermal resistance or thermal impedance. If the temperature is acquired during the functional operation of the converter, it can be used as a damage indicator of the power module. An increase of this parameter may be due to a rise of a thermal resistance and used as a detector of a solder layer delamination process [1]. The measurement is then used to validate global dimensioning in operating conditions. It can also be done during the lifetime of the converter in order to alert the user before its failure.

Three main methods are currently used to evaluate the temperature of power semiconductor devices [2]:

- Optical methods,

- Physical contact methods,

- Electrical methods.

The optical properties of semiconductor devices are temperature dependent. Thus many optical temperature indicators can be found, such as luminescence, Raman effect, refraction index [2], reflectance [3] or laser deflection [4-6]. The authors of power electronics studies often use the variation of infrared (IR) radiation with temperature: local infrared sensors [711], optical fibers [12-13], infrared microscope [14-15] and infrared camera [7,19-23].

The main advantage of the IR camera and the thermo-reflectance techniques is the possibility of directly obtaining a temperature map of the power device. For example, figure 1 shows the temperature measurement of the surface of an IGBT chip with an IR camera. The chip temperature is not uniform, the temperature difference being about $25^{\circ} \mathrm{C}$ between the center and side of the semiconductor chip. The infrared microscope [14] and the 2D radiometry [8,9] also allow for thermal mapping of the semiconductor device. In addition, the laser deflection technique [4-6] can be used to measure the temperature gradients directly inside the power semi-conductor. This possibility can be very interesting in order to validate electro-thermal models. However all these measurement methods require modifying the power module: the chip has to be seen by the optical system; the polymer package and the dielectric gel have to be removed. High voltage operating conditions are therefore limited. 


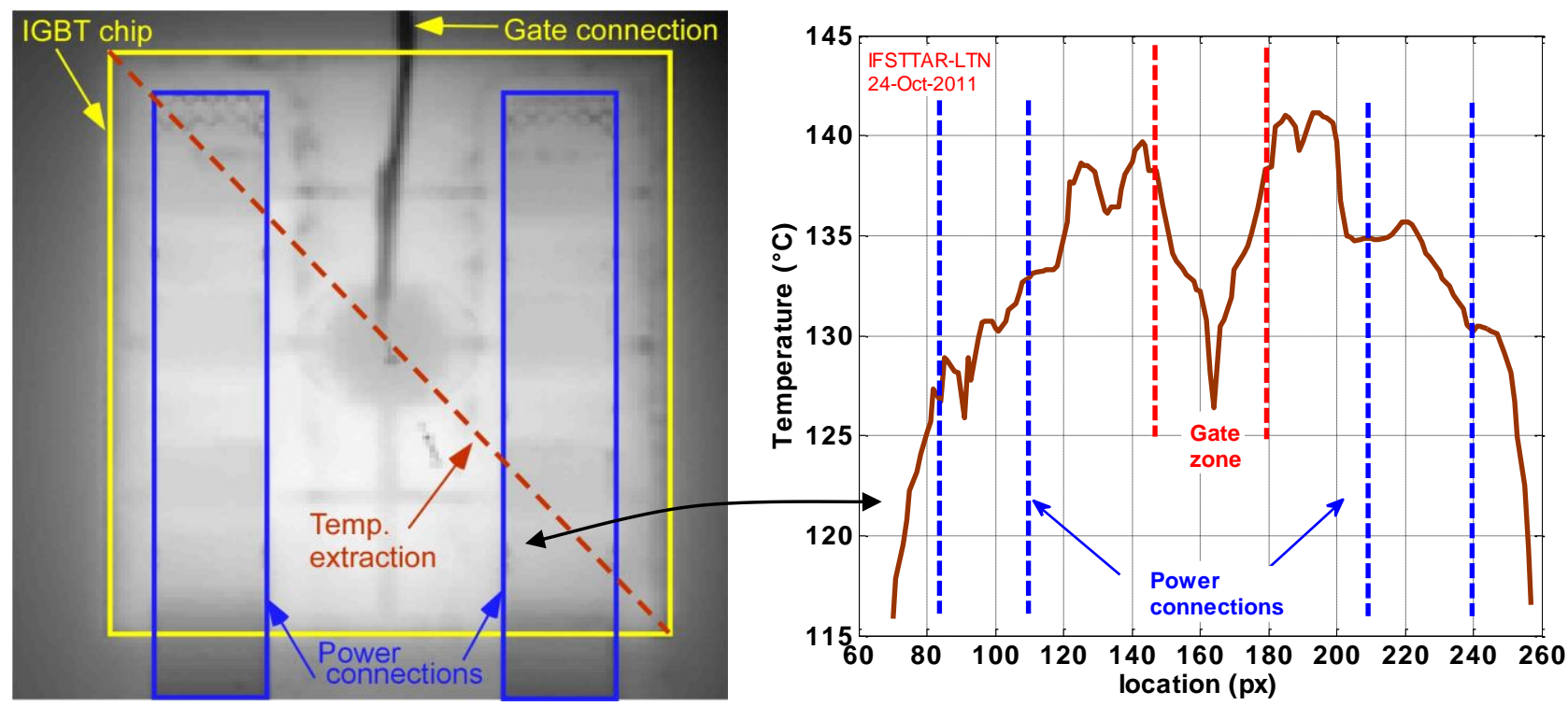

Fig. 1. Infrared imaging of a functioning IGBT chip

Nevertheless, one optical method that can be used with the dielectric gel is the measurement by optical fibers in direct contact with the power chip [12]. But this measure only gives a local temperature. For almost all optical methods, the measurement time is generally higher than a few milliseconds because of the electronic processing.

The device temperature measurement can also be obtained by making direct contact with the chip with a thermo-sensitive material. For example, solutions using liquid crystals or thermographic phosphors [2] can be found. The main solution is the use of thermal probes (thermistors or thermocouples). Less accurate methods use thermocouples with external diameters of hundreds of micrometers glued or soldered onto the chip surface [11,24-26]. In these cases, the dynamic response is not good and the measurement is local only. Brekel et al. [11] propose soldering the gate-resistor directly onto an IGBT chip and using the temperature dependence of its resistance to evaluate the semiconductor temperature. Finally, more accurate methods use microprobes [27]. Their small size, which leads to a low thermal capacitance, allows fast measurements without any heat transfer disturbances.

Apart from the use of the gate-resistor of an IGBT, all the methods outlined necessitate visual or mechanical access to the chip. This is the reason why today device temperature evaluation is often carried out using electrical methods. In this case, the thermal dependence of electrical properties of semiconductor devices is used to determine the temperature: the chip is itself the temperature sensor. The temperature can thus be evaluated using only voltage and current probes on packaged devices. However, this method only provides a "global" temperature; it is not possible to establish a temperature map and thus know the peak junction temperature. Blackburn [28] proposes a method for determining this peak junction 
temperature in the case of power bipolar transistors, but this has not been extended to other power devices. Furthermore, the problem of thermal mapping is also a problem in converters or in multi-chip modules where there are several devices in parallel. The voltage measurement only gives a global temperature of the different dies, and it is not possible to determine which one is the hottest or the coldest. This problem is discussed by Farjah et al. [29]. They propose an inverse method to determine the real temperature distribution between several paralleled chips. Such a method necessitates taking several measurements in different electrical conditions.

Despite these problems, temperature measurement by Thermo-Sensitive Electrical Parameters (TSEPs) is today the only way to carry out fast measurements on packaged devices with times shorter than $100 \mu \mathrm{s}$. This paper proposes a review of the different methods presented in the scientific literature. All these methods are then compared in terms of sensitivity, linearity, accuracy, genericity, calibration needs and possibility of characterizing the thermal impedance or the temperature during the operation of the converter. The measurement of thermo-sensitive parameters of wide band gap semi conductors is also discussed.

\section{BASIC PRINCIPLES OF TEMPERATURE MEASUREMENTS WITH TSEPS}

\section{A. Methodology}

Generally, two steps are necessary for the temperature measurement of a semi-conductor device. The first one is calibration, which is used to determine the relationship between the TSEP and the device temperature. The second is dissipation which conducts to use the TSEP in an applicative approach. During this last step, the power device is crossed by a high current that creates high heat losses. The temperature measurement is done during or just after this step. In case of thermal resistance or thermal impedance measurements, the dissipated power is generally continuous and is created by conduction losses. For on-line temperature measurements, the dissipated power is produced by both conduction and switching losses.

During the calibration step, the temperature is fixed by an external system - typically an oven, a dielectric bath or a temperature controlled heat sink. Then a current or a voltage under known electrical conditions is measured as a function of the temperature. During this step, the device dissipates an instantaneous power $\mathrm{P}_{\mathrm{m}}$. The self-heating of the device due to $\mathrm{P}_{\mathrm{m}}$ has to be negligible in order to obtain accurate measurements. Generally, this measure is carried out at a low power level $\mathrm{P}_{\mathrm{m}}$ largely lower than $1 \mathrm{~W}$. If $\mathrm{P}_{\mathrm{m}}$ is too high and therefore the self-heating is not negligible, the measurement time has to be as short as possible (from tens to hundreds of microseconds). 
The dissipation step depends on the device self-heating during the TSEP measurement. Two main methods are therefore used to carry out temperature measurements. They will be presented in the next paragraphs.

\section{B. Temperature measurement with a low $P_{m}$ value}

When the TSEP measurement induces a very low self-heating, the thermal characterization has to be carried out using two power levels: one for the dissipation $\left(\mathrm{P}_{\mathrm{c}}\right)$ and another for the device temperature measurement $\left(\mathrm{P}_{\mathrm{m}}\right)$. For example, figure 2 shows a technique that is commonly used to measure the thermal impedance of a power package. In this example, a power $\mathrm{P}_{\mathrm{c}}$ is dissipated into the power device in order to introduce self-heating. After temperature stabilization, the power is reduced to a low injection value $\mathrm{P}_{\mathrm{m}}$ where the self-heating is negligible. Note that, depending on the TSEP, the $\mathrm{P}_{\mathrm{m}}$ value can vary with temperature. The temperature decrease can then be directly deduced from this measurement. The initial temperature value $\mathrm{T}_{\mathrm{m}}$ can be estimated by extrapolation. Here, thermal impedance is measured during the cooling phase.

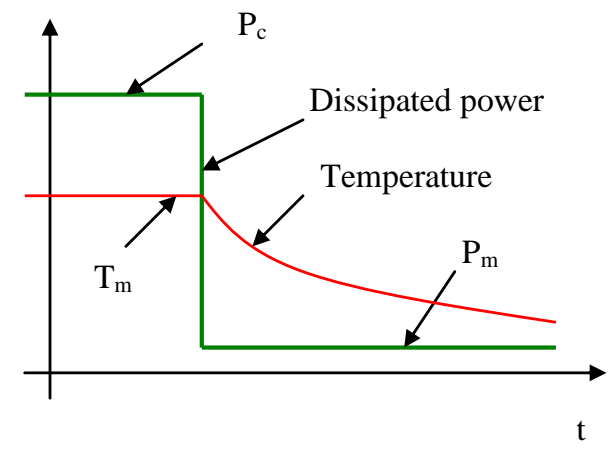

Fig. 2. Temperature measurement using a low calibration power $\mathrm{P}_{\mathrm{m}}$

Switching times are not instantaneous. During the transition from high to low power levels, electrical measurement therefore gives incorrect temperature values. Figure 3 shows the temperature measurement using $v_{\text {be }}(t)$ of a bipolar transistor under low emitter current as TSEP [30]. When the time is shorter than $6 \mu$ s, the measured temperature decreases sharply because of the switching phenomena. In figure 3, Blackburn [30] shows a linear extrapolation method where he assumes that the cooling process was one-dimensional (i.e. the temperature decreases linearly with the square root of time). With this extrapolation, it is possible to estimate the temperature $T_{m}$ at $t=0 \mathrm{~s}$ and then the device temperature before switching time. 


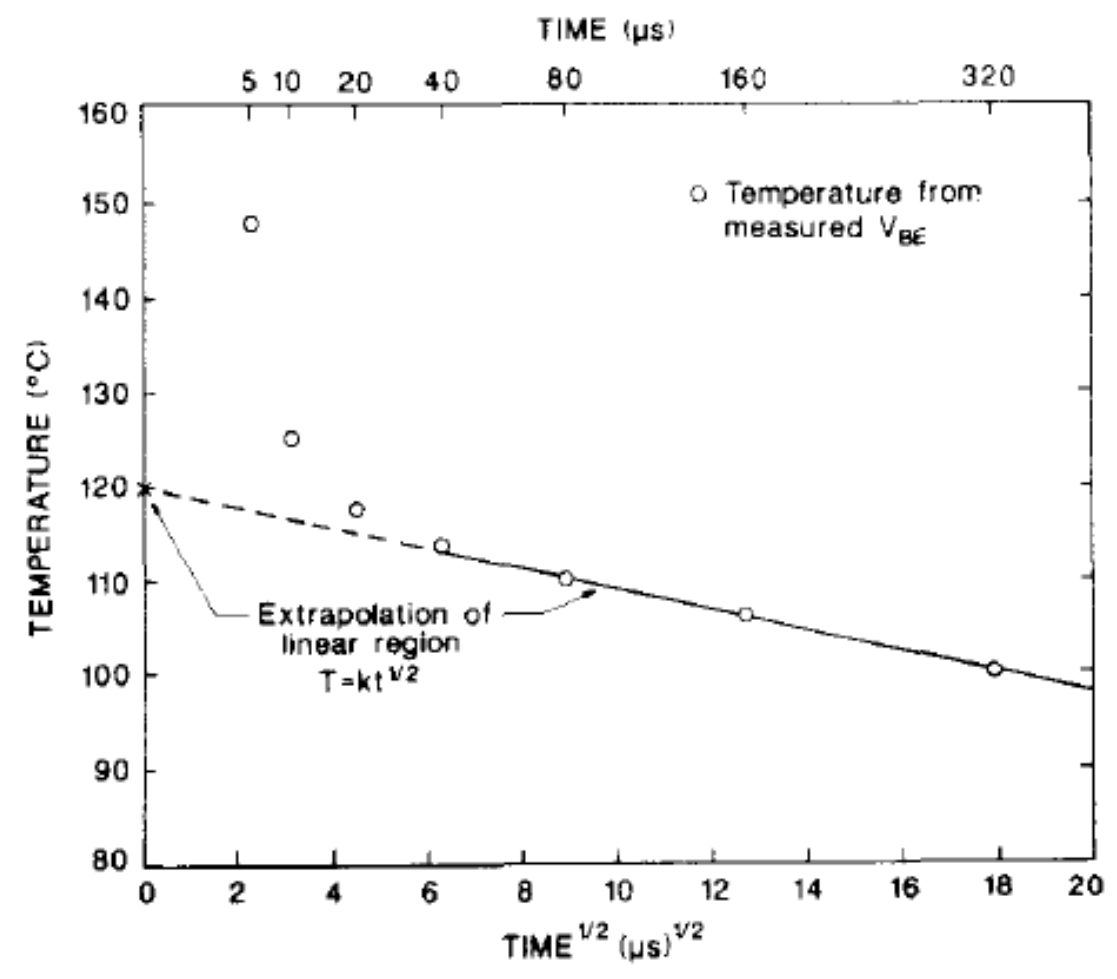

Fig. 3. Device temperature measurement of a bipolar transistor [30]

\section{Temperature measurement with a high $P_{m}$ value}

When the TSEP measurement induces a non negligible self-heating, the dissipated power $\mathrm{P}_{c}$ is generally the same than the measurement power $\mathrm{P}_{\mathrm{m}}$. Therefore the measurement of a thermal impedance can be done as shown in figure 4 . Here, the temperature measurement is make during the heating phase. In this case an extrapolation is also necessary to measure the temperature value $T_{i}$ before the self-heating. The thermal resistance measurement is done waiting the temperature stabilization.

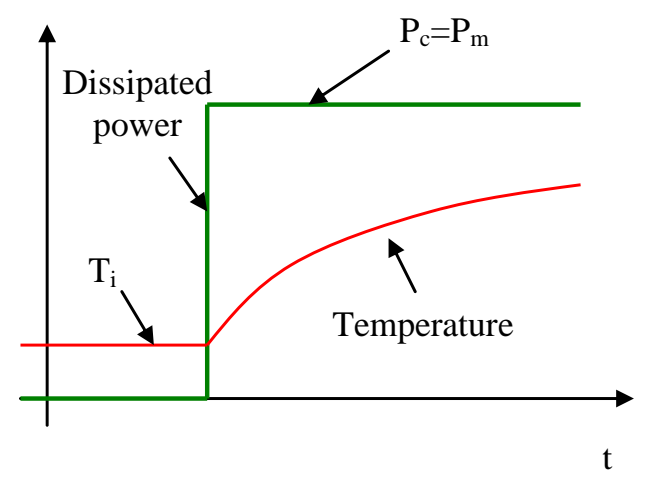

Fig. 4. Temperature measurement using a high calibration power $\mathrm{P}_{\mathrm{m}}$ 


\section{LITERATURE REVIEW ON THE MAIN TSEPS}

\section{A. TSEPs inducing a low self-heating}

1) Voltage measurement with a low current injection

The low current injection method is used in many industrial and academic works. Its main advantage is a very easy calibration step because the self-heating is negligible under normal conditions. The calibration step is made as depicted in figure 5. A current source feeds the power device, and the thermo-sensitive parameter is a voltage measured on the device under test (DUT). The current value is generally in the range $1 \mathrm{~mA}$ to hundreds of $\mathrm{mA}$ depending on the active area (i.e. the current rating of the device) and on the component type.

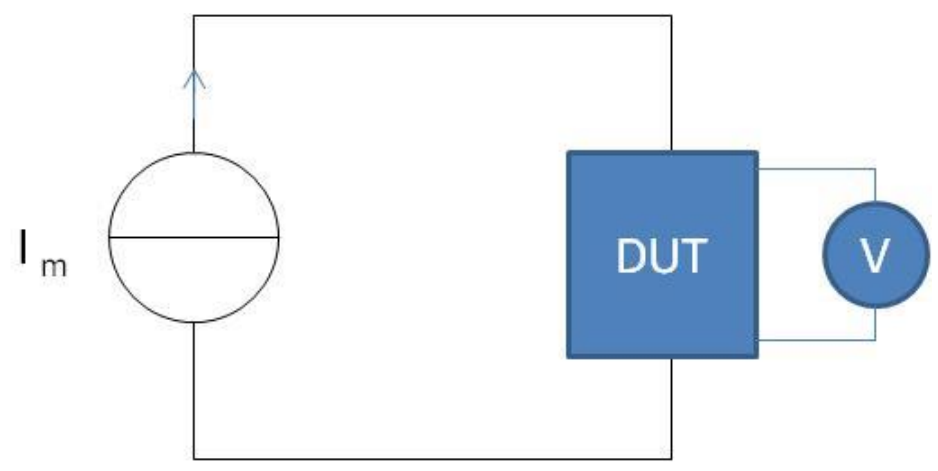

Fig. 5. Calibration step with a low current injection

The measurement of the forward voltage $\mathrm{V}_{\mathrm{f}}$ of a diode under low current is frequently used in the electronics field in general and also for the realization of temperature sensors. Of particular interest is the good linearity of the temperature measurement. Voltage dependence is generally close to $-2 \mathrm{mV} /{ }^{\circ} \mathrm{C}$ for silicon devices [31].

In the field of power electronics, this measurement method is widely used because almost all power devices have a PN junction in their structure. The method can therefore be used with diodes in forward polarization [31-35], MOSFET [36] in the off-state, base-emitter junction of bipolar transistors [28]. This method is also frequently used with IGBT [19,34,37-40]. In this case, the TSEP is the saturation voltage $\mathrm{V}_{\text {ce,sat }}$.

Figure 6 shows different device temperature measurement possibilities that can be used with diodes, IGBT or MOSFET. In each case, the electrical circuit allows for the injection of a high current $I_{c}$ for power dissipation and a low current $I_{m}$ for temperature measurement using an electrical thermo-sensitive parameter. In some cases, the $\mathrm{I}_{\mathrm{m}}$ source is not interrupted because this current value is generally much lower than $I_{c}$ with no significant heat generation. 


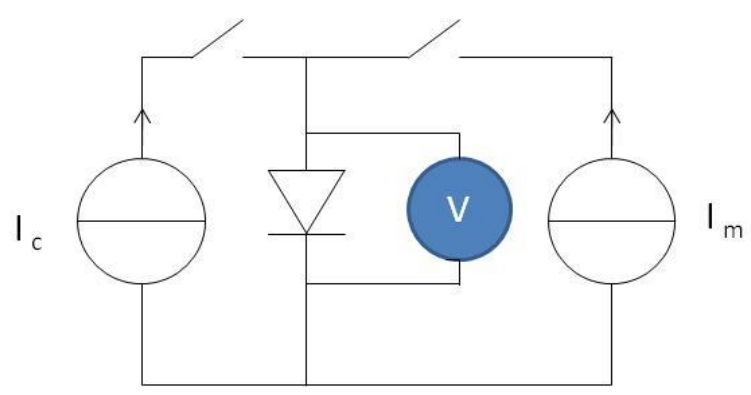

a. Diode

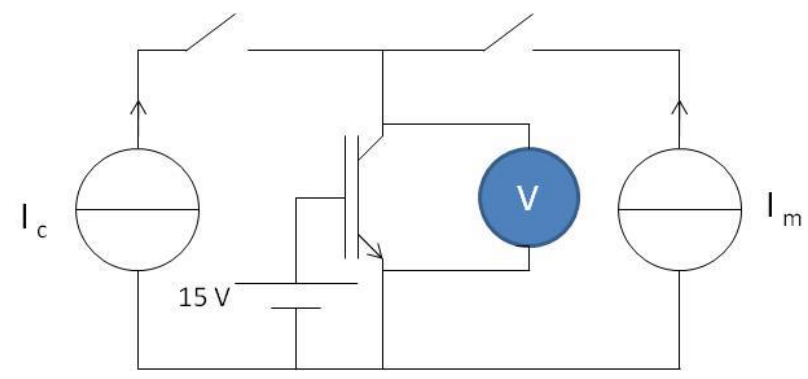

b. IGBT

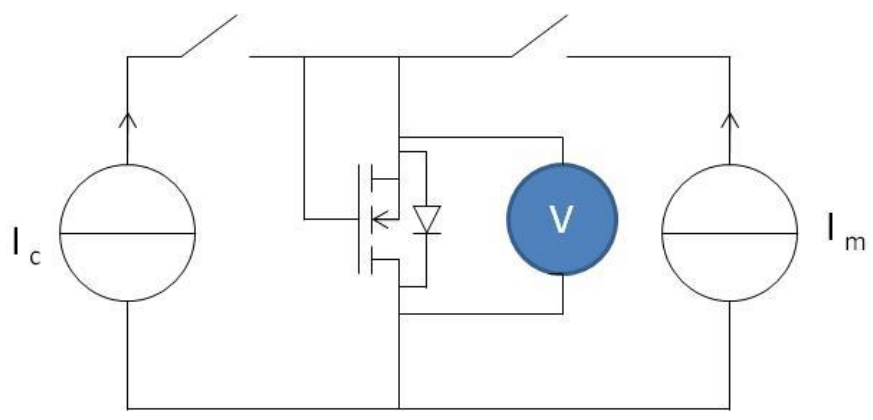

c. MOSFET

Fig. 6. Different electrical circuits for the measurement of the voltage under a low current

It is very important to choose a good measurement current value $\mathrm{I}_{\mathrm{m}}$. In the case of microelectronic devices, $\mathrm{I}_{\mathrm{m}}$ can easily be lower than 1mA. But for power devices, this current is generally higher. In fact, if it is too low, the relation between temperature and voltage is no longer linear in the whole temperature range. This has been demonstrated by Khatir et al. [32]. They measured the forward voltage drop of a power diode as a function of device temperature and for different measurement currents $I_{m}$. In their experiment, the current rating of the diode was 200A. In the same way for an IGBT (Infineon SIGC100T60R3), figure 7 clearly shows that a measurement current $\mathrm{I}_{\mathrm{m}}$ higher than $1 \mathrm{~mA}$ is needed to obtain a linear relationship for a $0^{\circ} \mathrm{C}$ to $175^{\circ} \mathrm{C}$ temperature range. 


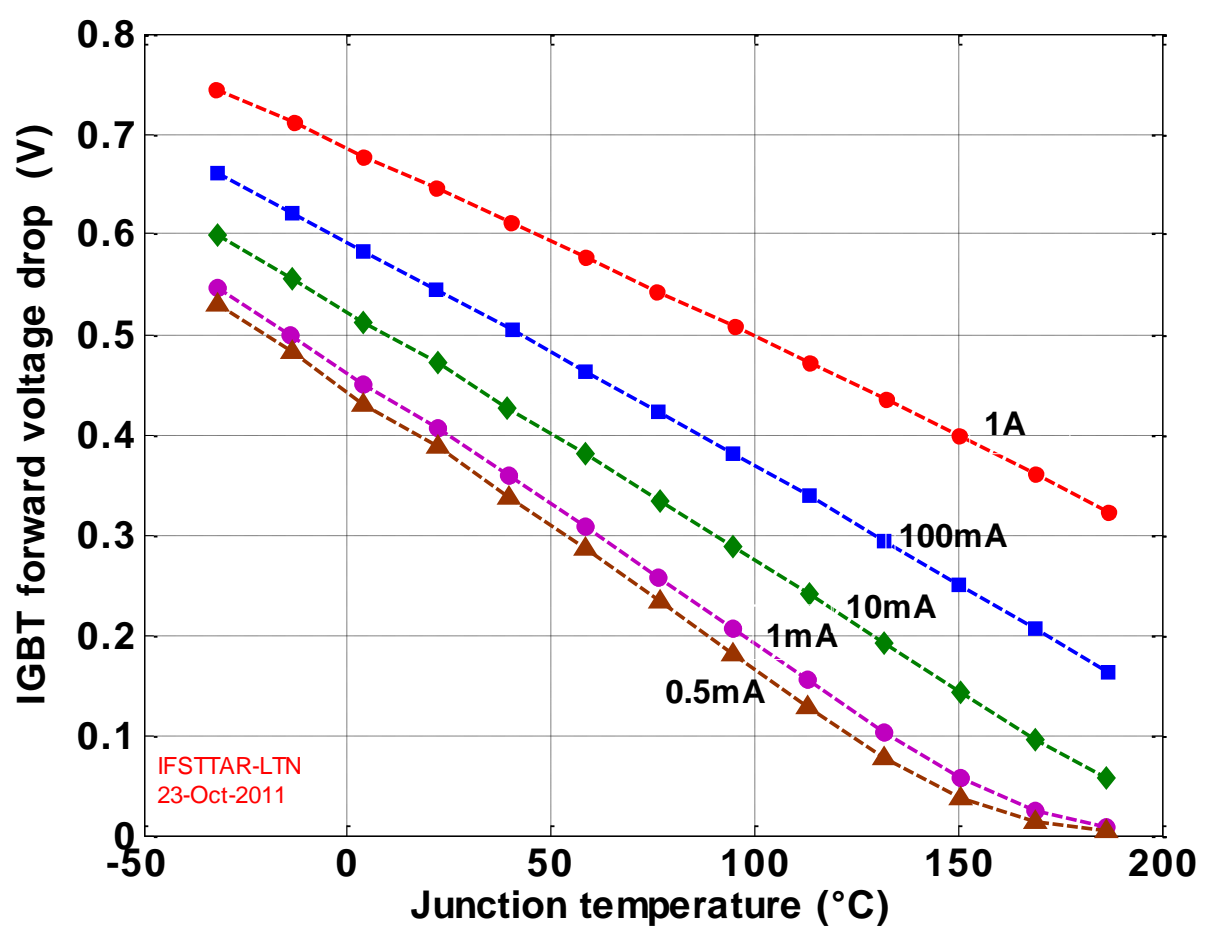

Fig. 7. Forward voltage of an IGBT as a function of the device temperature for different currents $\mathrm{I}_{\mathrm{m}}$

The temperature of a MOSFET in on-state can be estimated using the measurement of the drain-source voltage under a low current [41]. The measurement can be carried out with the electrical circuit from figure $6 \mathrm{~b}$, replacing the IGBT by a MOSFET. It is important to notice that there is a real difference between this measurement and the measurement obtained with a diode forward voltage or with an IGBT saturation voltage. In fact, for a diode or an IGBT, the equivalent ohmic resistance of the semi-conductor device is much higher than that of electrical connections inside the power module. The influence of the connections can therefore easily be neglected. That is not the case for MOSFET devices because their onstate resistance is generally lower than $100 \mathrm{~m} \Omega$. In some cases, the variation of the connection resistance with temperature cannot be neglected. The main problem is due to the temperature difference between connections and chips which is not comparable during the calibration step and dissipation step. In the first case, the temperatures of connections are the same as those of the power chips whereas in the second case they are different.

\section{2) Measurement of the threshold voltage}

The threshold voltage $V_{\text {th }}$ is used to evaluate the temperature of MOSFET [41-42] and IGBT [19,29,37,39,43-44]. Generally the calibration step is made with a very low current regulation acting on the gate voltage (figure 8a) or simply with a connection of the gate and the collector (drain) electrodes (figure 8b). The current value is a few mA so as to work 
as close as possible to the actual threshold voltage. Figure $8 \mathrm{c}$ shows the dependence of the measured voltage as a function of temperature and for different collector-emitter voltages and different current values for an IGBT chip (Infineon SIGC100T60R3) and using the method described in figure 8a. This example shows that the current value has to be higher than a minimal value in order to have a correct measurement for high temperatures. The influence of the voltage value is very low. The sensitivity depends on the semiconductor chip. It is generally in the $-2 \mathrm{mV} /{ }^{\circ} \mathrm{C}$ to $-10 \mathrm{mV} /{ }^{\circ} \mathrm{C}$ range.

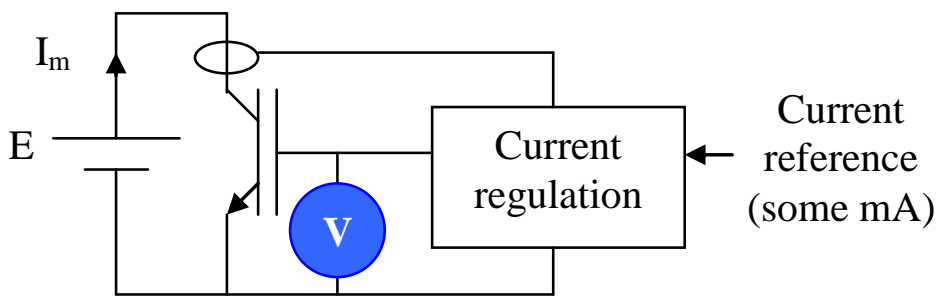

a. Electrical circuit \#1 for the calibration step

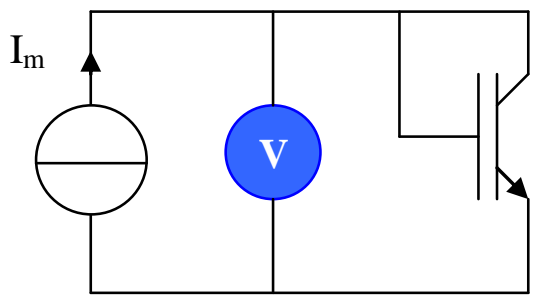

b. Electrical circuit \#2 for the calibration step

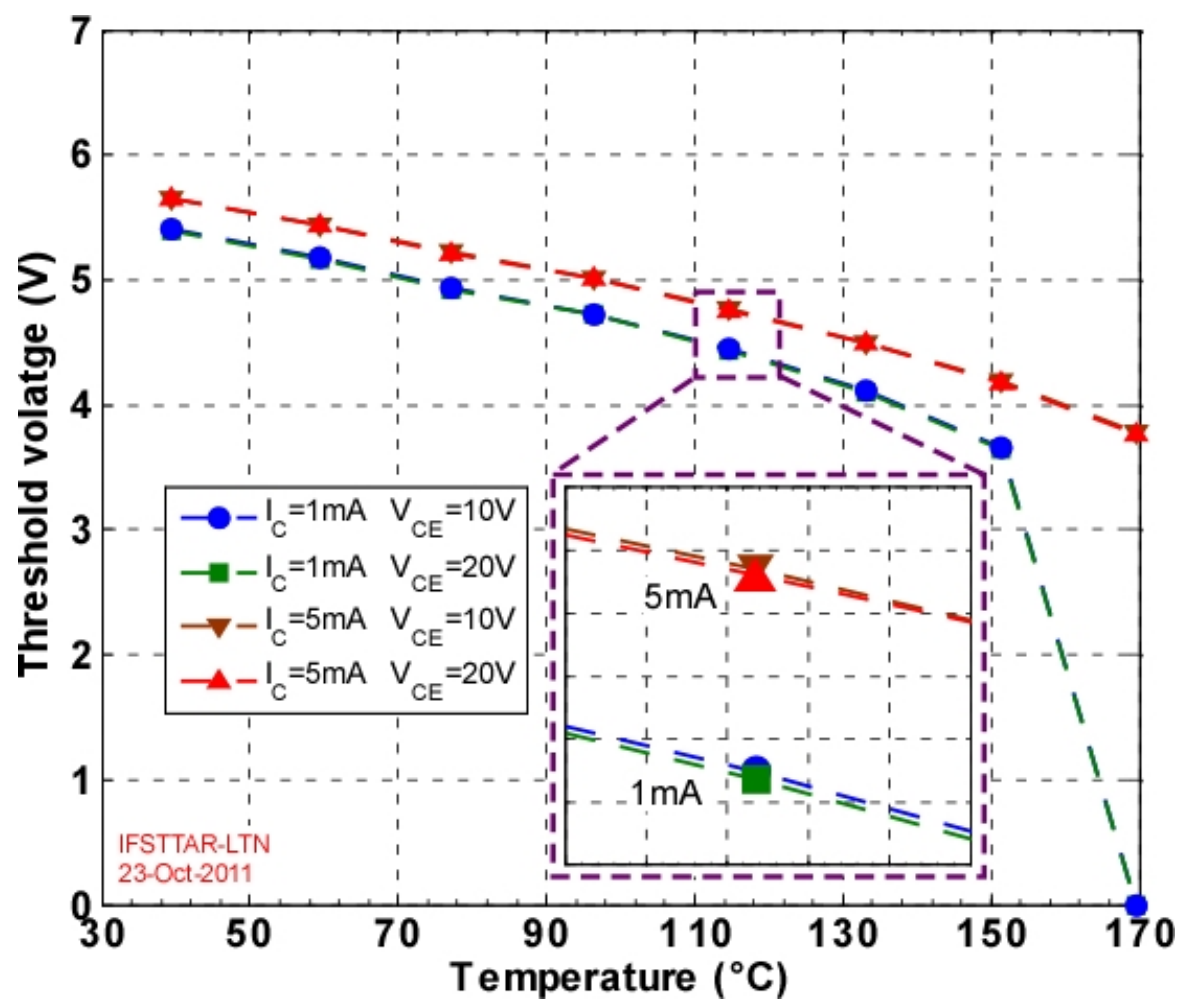

c. Threshold voltage as a function of temperature for different current and voltage values (electrical circuit \#1)

Fig. 8: Calibration step of the threshold voltage method 
Cao et al. [43] use the measurement method described in figure 8a. For temperature measurements during dissipation of the device, they implement a current regulation with two current levels: one for dissipation, and another for the measurement. Huang et al. [44] use the other method (figure 8b). For the IGBT temperature measurement, they use two current sources. The principle is the same than this presented in figure $6 \mathrm{~b}$ but connecting the gate and collector electrodes.

\section{B. TSEPs inducing a non negligible self-heating}

1) Voltage measurement with a high current injection

In this method, a high current is injected into the power device. The thermo-sensitive parameter is the drain-source voltage in on-state for MOSFET [45], the emitter-collector voltage in on-state for IGBT [46-47], and the forward voltage for diodes [47]. The main objective of the calibration is to obtain the static current-voltage characteristic of the semi-conductor device as a function of temperature. Two methods are discussed in the literature for the calibration step: it is possible to use the electrical circuit presented in figure 9 [46]. The current value is I when the switch is open and zero otherwise. A curve tracer can also be used [47].

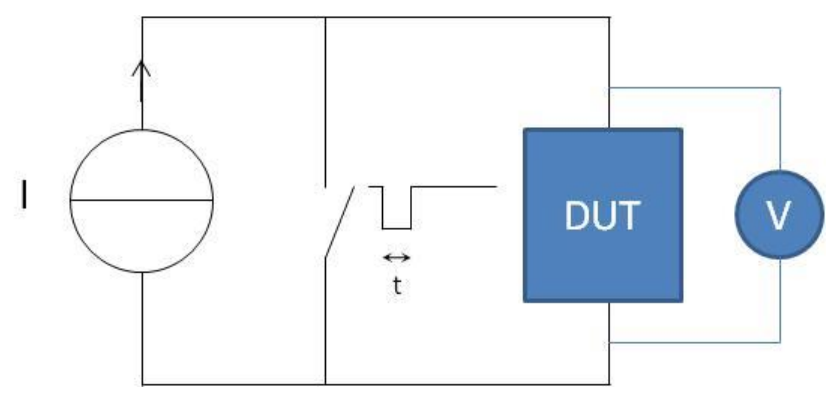

Fig. 9. Electrical circuit for the calibration step with a high current injected in the device

The measured voltage is largely dependent on the current value. The calibration step is therefore often carried out by measuring the voltage dependence on both temperature and current. Figure 10 shows the evolution of the saturation voltage of an IGBT chip (Infineon SIGC100T60R3 - $\mathrm{V}_{\mathrm{ge}}=15 \mathrm{~V}$ ). The sensitivity of this TSEP depends largely on the collector current $I_{c}$ level. In fact, it is negative for lower current values and positive for higher values. The temperature measurement is not possible for medium current values (about $60 \mathrm{~A}$ in this example). 


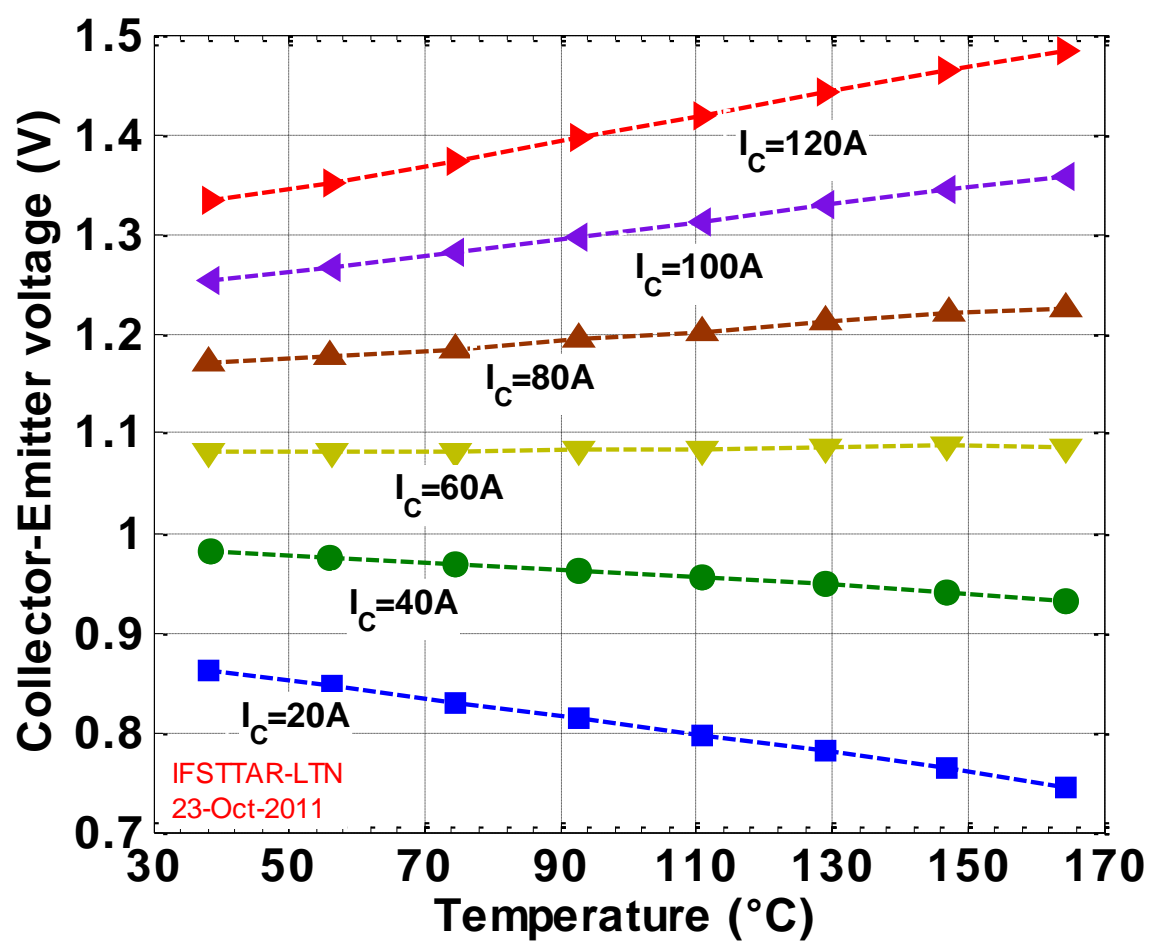

Fig.10. Saturation voltage of an IGBT chip as a function of temperature and for different current values

This method appears to be very useful especially for temperature measurement management during converter operation. But its implementation is not so easy because the voltage is very different when the device is in the off-state (a few hundreds Volts) and when it is in the on-state (a few Volts). The measuring electrical circuit has to allow for accurate measurements at low voltage and has to be protected against high voltage. Kim and al. [47] and Koenig et al. [45] present some specific electronic circuits which fulfill these requirements.

\section{2) Measurement of the gate-source or gate-emitter voltage}

The principle of this measurement is very close to this of the threshold voltage using the method described in figure $8 \mathrm{a}$ but in this case the current is higher and creates a non negligible self-heating [19]. Figure 11 presents the evolution of this TSEP as a function of temperature in the case of an IGBT chip (Infineon SIGC100T60R3). This figure shows that it depends largely on the collector current value and that the collector-emitter voltage does not influence a lot the measurement. In order to improve the calibration measurement, Berning et al. [48] propose an original test circuit. It allows electrical disturbances to be reduced during switching time. The sensitivity of this TSEP is very close to the threshold voltage one. 


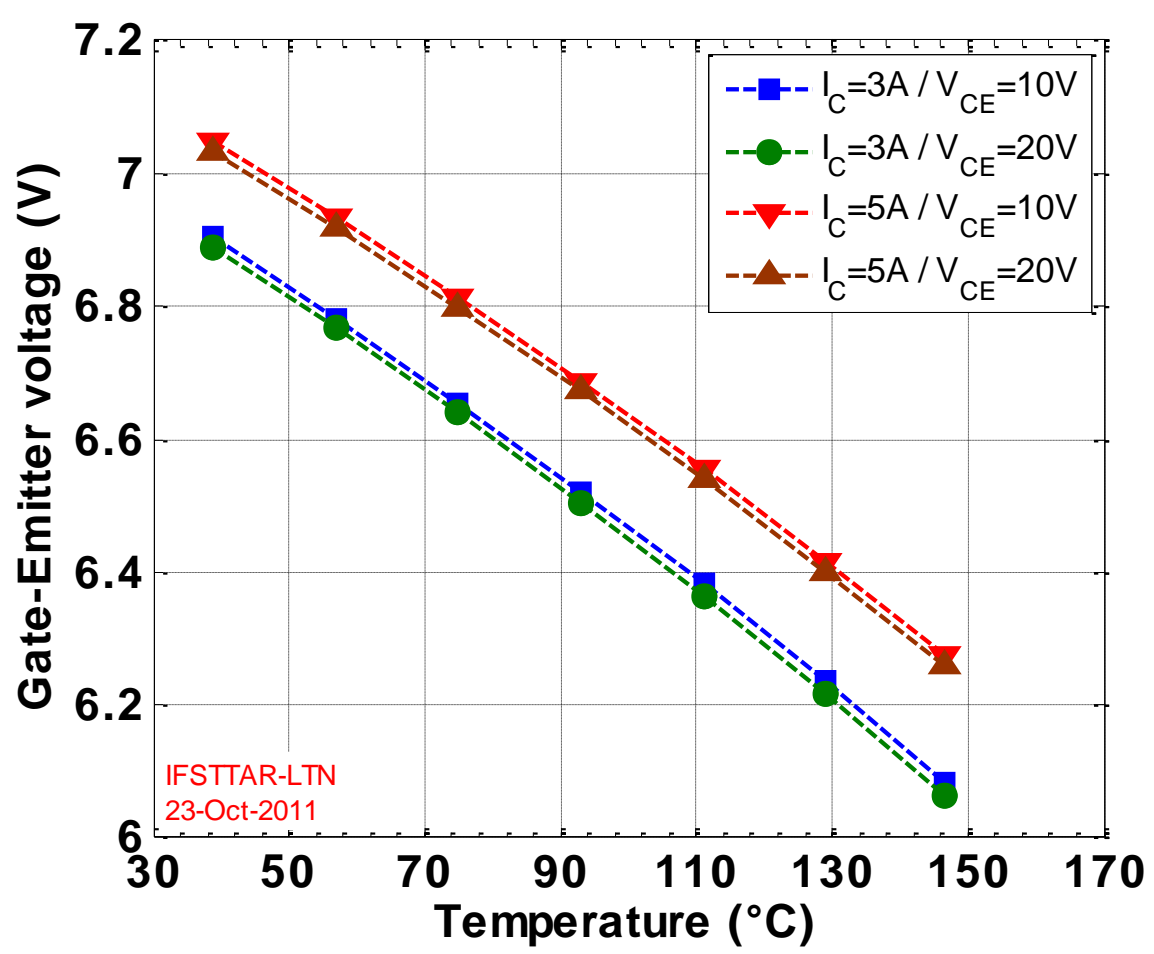

Fig. 11: Gate-emitter voltage under a high current as thermo-sensitive parameter

3) Measurement of the saturation current

In the case of IGBT or MOSFET, the saturation current can be used as a thermo-sensitive parameter [19,33,37,49-51]. For this measurement, a voltage is applied to power electrodes. The gate-emitter (or gate-source) voltage value $\mathrm{V}_{\text {gem }}$ is slightly higher than the threshold voltage $\mathrm{V}_{\text {th }}$ of the device. A current probe measures the resulting saturation current $\mathrm{I}_{\text {sat }}$ (figure 12a). This measurement provides a temperature estimation because of the dependence of electron mobility and threshold voltage on temperature [37]. Figure 12b shows an example of saturation current value as a function of temperature (Infineon SIGC100T60R3 IGBT chip). It clearly shows that this thermo-sensitive parameter is not linear. The exponential shape leads to an increase of sensitivity with temperature. Hence the measurement is less precise for low temperatures. As for the gate-emitter voltage method, this TSEP does not depend a lot on the collector-emitter voltage value.

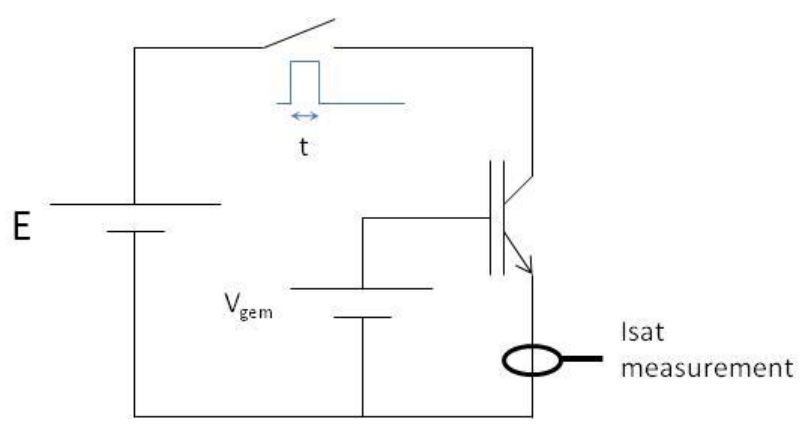


a. $\mathrm{I}_{\mathrm{sat}}$ measurement principle

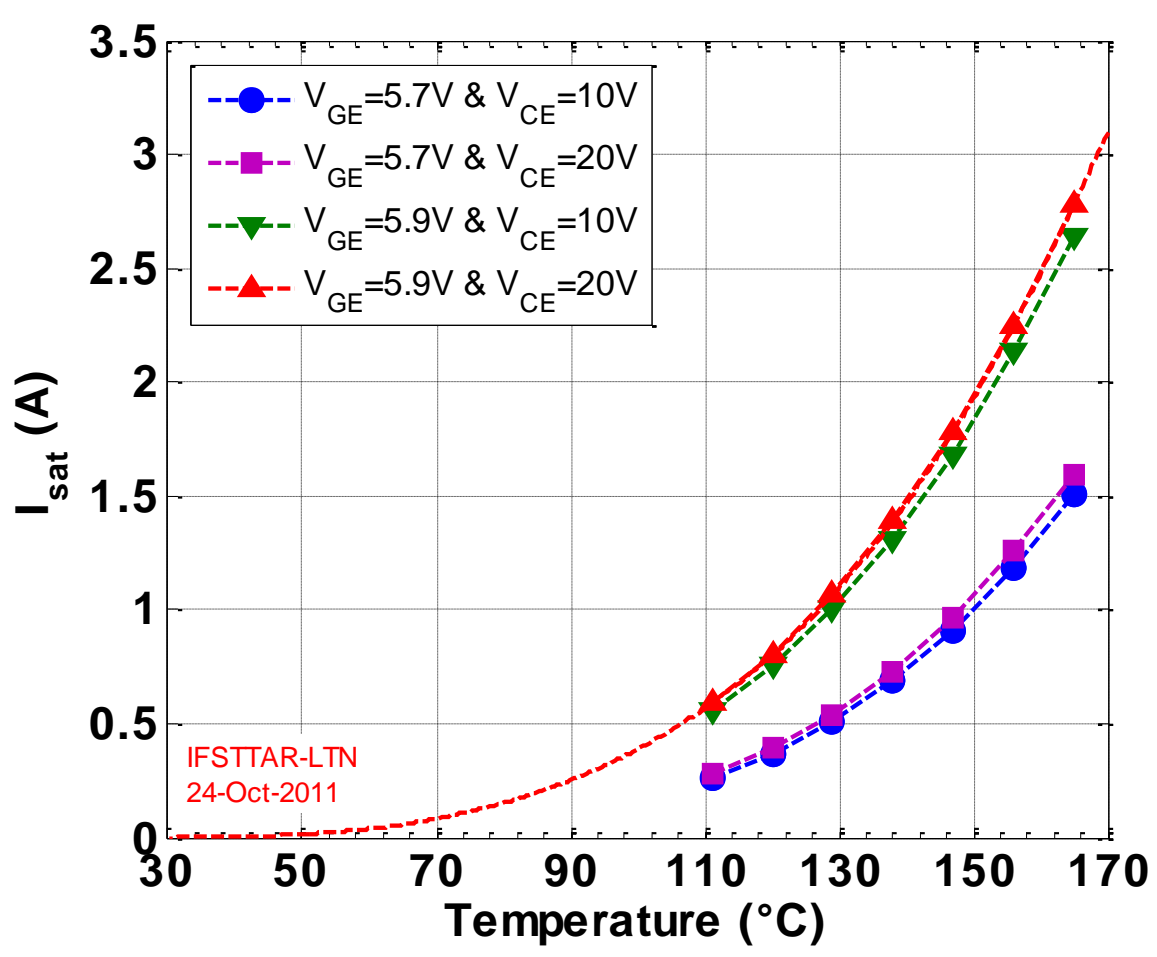

b. $\mathrm{I}_{\text {sat }}$ value as a function of temperature

Fig. 12. Temperature measurement with the saturation current as a thermo-sensitive parameter

4) Switching behavior

During operation of the converter, the temperature measurement of an IGBT or a MOSFET chip can be made during the switching time. A first TSEP is thus the turn-on delay [42,53-54]. Figure 13a shows how this measurement can be carried out [53]. In this study, a digital circuit (FPGA) monitors the evolution of both the gate-emitter voltage $\mathrm{vge}_{\mathrm{ge}}(\mathrm{t})$ and the collector current $i_{c}(t)$ via two analog-digital converters. It detects the rising gate-emitter voltage, starts running a counter $(100 \mathrm{MHz})$, detects the rising edge of the collector current and stops the counter. In this example, the delay time is about $1500 \mathrm{~ns}$. As shown in figure 13b, this delay increases linearly with the temperature [53]. Under these conditions, sensitivity is close to $2 \mathrm{~ns} /{ }^{\circ} \mathrm{C}$. This is a delicate measurement because of the very short time span. Chen et al. [42] therefore suggest raising the gate resistance value in order to increase switching time when a temperature measurement is required. The turn-on delay measurement as a thermo-sensitive parameter is of great interest because it is not influenced by the current value (figure 13b).

The turn-off delay can also be used as a thermo-sensitive parameter. Kuhn and Mertens [53] show that sensitivity is close to that obtained with the turn-on delay. Another solution proposed by various authors is the use of the current slope variation 
with temperature, during the turn-on [52-54]. However, these methods are less interesting because the measured time depends greatly on the collector current before switching and on the DC bus voltage [53].

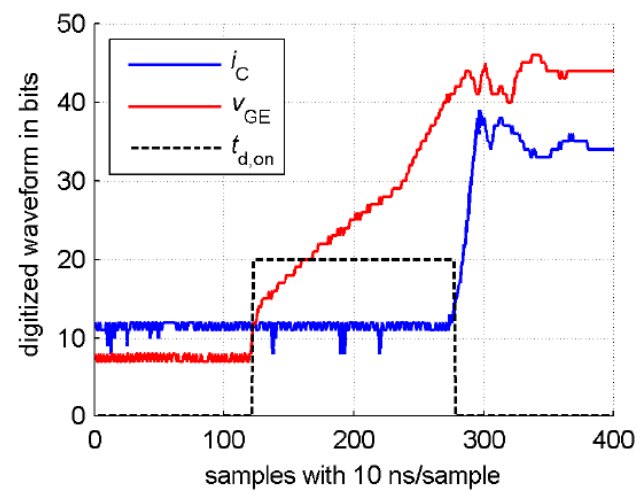

a. Turn-on delay measurement

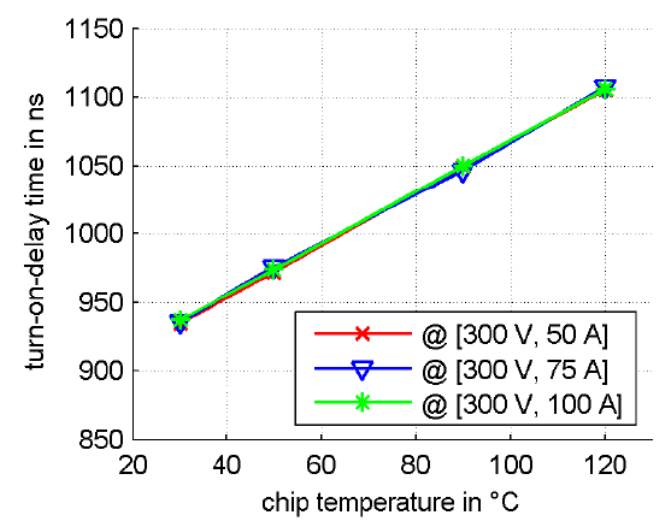

b. Turn-on delay as a function of temperature

Fig. 13: Turn-on delay as a thermo-sensitive parameter [53]

\section{DISCUSSION}

\section{A. Comparison of the different TSEPS}

1) Presentation of the different comparison criteria

All the previously presented TSEP are used in different studies but they are hardly compared each other. It is therefore interesting to know their strengths and weaknesses according to the intended application. Seven comparison criteria will be used in this paper: the sensitivity of the TSEP, its linearity, the calibration needs, the genericity, the accuracy the possible measurement of the thermal impedance and the possibility of doing on-line temperature measurements.

\section{a. Sensitivity}

Apart from the temperature measurement during the switching time, all TSEPs are voltage measurements. In fact the saturation current is often measured with a shunt resistor. In order to obtain a precise measurement, the sensitivity of each TSEP has not to be largely lower than the range of the voltmeter. It is therefore possible to compare these TSEPs using the 
following ratio:

$$
S=\frac{|S|}{\left|v a l_{\text {max }}\right|}
$$

where $s\left[\mathrm{~V} /{ }^{\circ} \mathrm{C}\right]$ is the sensitivity of the TSEP and $v a l_{\max }[\mathrm{V}]$ is the maximum value of the TSEP in the temperature range. The comparison was made using the measurements obtained with an Infineon SIGC100T60R3 IGBT chip in the $110^{\circ} \mathrm{C}$ $150^{\circ} \mathrm{C}$ temperature range. Table I summarizes the results with an evaluation of the test ratio under different test conditions. It shows that the best parameter in term of sensitivity is the saturation current. The voltage under a high current seems to be the worst case. Furthermore, unlike other TSEP, this parameter is strongly dependent on the test conditions. Indeed figure 10 shows that the slope of the saturation voltage of the IGBT $(600 \mathrm{~V}-200 \mathrm{~A})$ as a function of the temperature varies with the collector current, is very low for current levels close to $60 \mathrm{~A}$ and is negative for lower current levels.

TABLE I: COMPARISON OF SENSITIVITY RATIO $S$ FOR EACH VOLTAGE TSEP

\begin{tabular}{|c|c|c|c|c|c|}
\hline TSEP & $\begin{array}{l}\text { Voltage under } \\
\text { a low current }\end{array}$ & Threshold voltage & $\begin{array}{l}\text { Voltage under } \\
\text { a high current }\end{array}$ & Gate-Emitter voltage & Saturation current \\
\hline Test conditions & $I_{m}$ from $10 \mathrm{~mA}$ to $1 \mathrm{~A}$ & $\begin{array}{l}\mathrm{I}_{\mathrm{c}}=1 \mathrm{~mA} \text { or } 5 \mathrm{~mA} \\
\quad \text { and } \\
\mathrm{V}_{\mathrm{ce}}=10 \mathrm{~V} \text { or } 20 \mathrm{~V}\end{array}$ & $\mathrm{I}_{\mathrm{c}}$ from $20 \mathrm{~A}$ to $120 \mathrm{~A}$ & $\begin{array}{c}\mathrm{I}_{\mathrm{c}}=3 \mathrm{~A} \text { or } 5 \mathrm{~A} \\
\text { and } \\
\mathrm{V}_{\mathrm{ce}}=10 \mathrm{~V} \text { or } 20 \mathrm{~V}\end{array}$ & $\begin{array}{c}\mathrm{V}_{\mathrm{ge}}=5.7 \mathrm{~V} \text { or } 5.9 \mathrm{~V} \\
\text { and } \\
\mathrm{V}_{\mathrm{ce}}=10 \mathrm{~V} \text { or } 20 \mathrm{~V}\end{array}$ \\
\hline Sensitivity ratio $S$ & $\begin{array}{l}\text { From } 4.10^{-3} \mathrm{~K}^{-C^{-1}} \\
\text { to } 1.10^{-2} \mathrm{~K} \cdot \mathrm{C}^{-1}\end{array}$ & $\begin{array}{l}\text { From } 3 \cdot 10^{-3} \mathrm{~K}^{-C^{-1}} \\
\text { to } 5 \cdot 10^{-3} \mathrm{~K} \cdot \mathrm{C}^{-1}\end{array}$ & $\begin{array}{l}\text { From } 0 \mathrm{~K} . \mathrm{C}^{-1} \\
\text { to } 1.10^{-3} \mathrm{~K} . \mathrm{C}^{-1}\end{array}$ & Close to $1.10^{-3} \mathrm{~K} \cdot \mathrm{C}^{-1}$ & Close to $2.10^{-2} \mathrm{~K}^{-\mathrm{C}^{-1}}$ \\
\hline
\end{tabular}

The sensitivity ratio of the turn-on delay is close to $10^{-3}{ }^{\circ} \mathrm{C}^{-1}$. It is therefore comparable with other TSEP. However the sensitivity value of $2 \mathrm{~ns} /{ }^{\circ} \mathrm{C}$ is very low and do not permit an easy accurate temperature measurement.

\section{b. Linearity}

The linearity is an interesting indicator for the data processing. It is also important for the calibration step because a linear TSEP does not need a lot of measurement points. The most linear TSEPs are the measurement of a voltage under a low or a high current $[32,47]$. However in the case of the low current, the current value has to be high enough in order to carry out measurements in high temperature ranges. The turn-on delay seems to be also linear but there are not enough experimental results in the literature in order to give a good conclusion. The saturation current is not linear at all.

The gate-emitter voltage and the threshold voltage have a parabolic shape. However if the temperature range is relatively low, it is possible to assume that they are linear. This approximation was made by different authors $[43,48]$.

\section{c. Calibration needs}

Every TSEP needs a calibration step. Nevertheless this procedure can be more or less long if a TSEP is chosen instead of another. In fact the linearity could reduce the measurement points number as mentioned above. Furthermore, a TSEP value 
can be different from a chip to another having the same reference and the same temperature.

For example, the threshold voltage of an IGBT chip has a non negligible variation using different chips with the same reference. This has been stated by Berning et al. [48]. Therefore a calibration process is needed for each IGBT in a same power module if the TSEP depends on the threshold voltage i.e. in the case of the gate-emitter voltage [19], the saturation current [19] and the switching delays. The problem would be identical with MOSFET chips.

The measurement of a voltage under a low current in the case of diodes, IGBT and MOSFET in off-state, is therefore better in terms of calibration needs because it is linear and because its variation is very low from one chip to another with the same reference. Authors [19] report a variation of about several $\mathrm{mV}$ i.e. several ${ }^{\circ} \mathrm{C}$ in case of IGBT chips. This can be really sufficient for lots of thermal studies.

In the case of the measurement of a voltage under a high current, the TSEP depends both on the semiconductor part and on its electrical connections because the impedance of the chip is very low in these electrical conditions. The measurement has therefore to be made for each chip because the electrical connections are different from a chip to another. The same problem could be observed using the measurement of a voltage under a low current in the case of a MOSFET in on-state.

\section{d. Genericity}

Two TSEPs can be used with every power semi-conductor chip. They are the measurement of a voltage under a low or a high current. On the other hand, the threshold voltage, the gate voltage, the saturation current and the switching times can only be used with transistors.

e. Accuracy and damage robustness

The temperature value given by the measurement of a TSEP is a global value of the inhomogeneous chip temperature. But is this temperature representative of the real chip temperature ? It is difficult to accurately answer this question because the majority of the cited papers does not compare the chip temperature obtained with the TSEP and the temperature obtained with a more direct measurement method.

However, several authors have compared the temperatures given by an IR camera and by the measurement of the voltage under a low current in the case of IGBT $[19,23,47]$ or diodes [47]. All these results show that the temperature value given by this TSEP is really close to the mean surface temperature of the chip, the temperature difference being lower than $3^{\circ} \mathrm{C}$. The same comparison is made with the saturation current and the gate-emitter voltage in the case of an IGBT chip [19]. The temperatures given by these TSEP seem to be also close to the mean surface temperature (temperature difference lower than $\left.3^{\circ} \mathrm{C}\right)$. 
In the case of diodes and IGBT chips, Perpina et al. [47] compare the results given by the measurement of the voltage under a high current and these given by IR measurements. The results are really amazing because the temperature difference between both measurements can be higher than $50^{\circ} \mathrm{C}$. This method is therefore not accurate. In order to understand this problem, Perpina et al. [47] explain that the measured voltage depends on both the semiconductor (static characteristic) and the resistance of the electrical connection. This leads to two main problems. First, the connection temperature is not the same during the calibration step and during temperature measurement. Since connection resistance varies with temperature, significant measurement errors can be created. Second, the connections age with power thermal cycling due to CTE differences in the materials of the power modules (wire bonding lift-off or cracks, etc...). The voltage under a high current therefore changes with time, and the temperature measurement is no longer accurate.

The problem of the aging could also be a problem for the TSEPs depending on the threshold voltage. In fact Smet [55] reports a variation of the threshold voltage with the operation time. A calibration procedure after aging is therefore needed in order to have accurate measurements.

At the moment, the accuracy of the temperature measurements during the switching time is not known because of the lack of data in the literature. However these measurements have to be made cautiously because of the influence of numerous electrical parameters: gate resistor, gate voltage, stay inductance, etc... It is thus important to carry out the calibration step in the same configuration (package) as that used during the measurement process.

\section{f. Measurement of a thermal impedance $Z_{\text {th }}$}

As said in section II, the measurement of a thermal impedance can be made during the cooling phase (case of the TSEPs inducing a low self-heating) or during the heating phase (other cases). The voltage measurement under a low current and the threshold voltage can therefore be used easily for a $Z_{\text {th }}$ measurement in the cooling phase.

For the measurement in the heating phase, it is important to have a constant dissipated power $\mathrm{P}_{\mathrm{m}}$. The measurement of the switching time can therefore not be used. The gate-emitter voltage is well adapted for such a measurement because the current is controlled by a regulation loop and the collector-emitter voltage is imposed by a voltage supply. The saturation current cannot be used because the variation of the current with the temperature induces a dissipated power variation during the heating phase. There is the same problem with the measurement of the voltage under a high current because the impedance of the chip varies with temperature.

\section{g. On-line temperature measurements}

Two TSEPs are well adapted for temperature measurements during the operation of the converter. They are the switching 
times and the voltage under a high current. However other TSEPs can also be used. In the case of inverters, Smet [55] and Arbanas [56] propose making the temperature measurements with the voltage under a low current when the load current value is close to $0 \mathrm{~A}$. They state that the inverter operation is not influenced by such a measurement. In this application, the threshold voltage could also be used but the driver circuit would be more complex.

Bergogne et al. [50] propose an original method based on the use of the saturation current of an IGBT chip in a chopper. Figure 14 shows the principle of such a measurement: during the off-state (the diode of the chopper is conducting), the gateemitter voltage swings from a negative value (IGBT off) to a value just higher than the threshold voltage. During this phase, the collector current of the IGBT is measured giving an estimate of the temperature. However, this interesting method still creates certain problems: the gate-emitter value has to be very accurate; and the current measurement is difficult because the value of the saturation current is much lower than the collector current during the IGBT on-state. The principle of this method is the derivation of a small part of the power current in the characterized power device. Therefore a temperature measurement could also be made using the gate-emitter voltage as TSEP but keeping the problem of the current measurement.

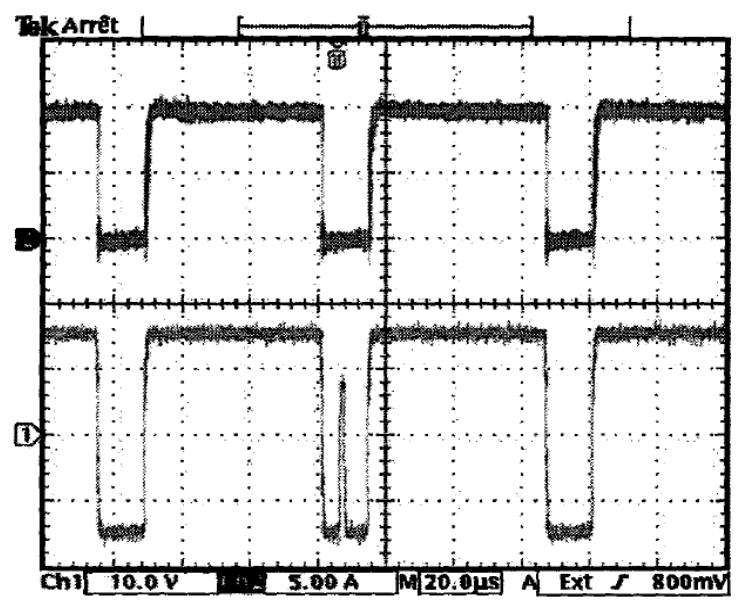

Fig. 14. Gate-emitter voltage (channel 1) and collector current (channel 2) for an IGBT on-line temperature measurement using the saturation current as a thermo-sensitive parameter [50]

2) Synthesis

Using the different statements given in the previous paragraph, figure 15 proposes a comparison of the different TSEPs using all defined criteria. A radar graph is proposed for each TSEP. In this graph, a point near the periphery means that the comparison criterion is favorable for the TSEP. Contrary a point near the center means that the criterion is poor. For the switching time (figure 15f), the accuracy criterion is not mentioned because of the lack of data in the scientific literature.

Comparing figure 15a to the others, it is easy to understand why the voltage under a low current is the most used method. 
In fact, apart from the on-line measurements, all the comparison criteria are very good. For the measurement of the thermal impedance of a package it seems to be the more reliable and simple parameter even if this measurement could also be carried out with the threshold or the gate-emitter voltages. The saturation current is limited to the measurement of one temperature i.e. to the measurement of thermal resistances.

At the moment, the measurement of on-line temperatures seems to be an unsolved problem. In fact the measurement of the voltage under a high current does not give accurate values and the use of switching times has not been validated by any measurement using a more direct method like IR camera. The use of other TSEPs is possible but limited to several converter structures.

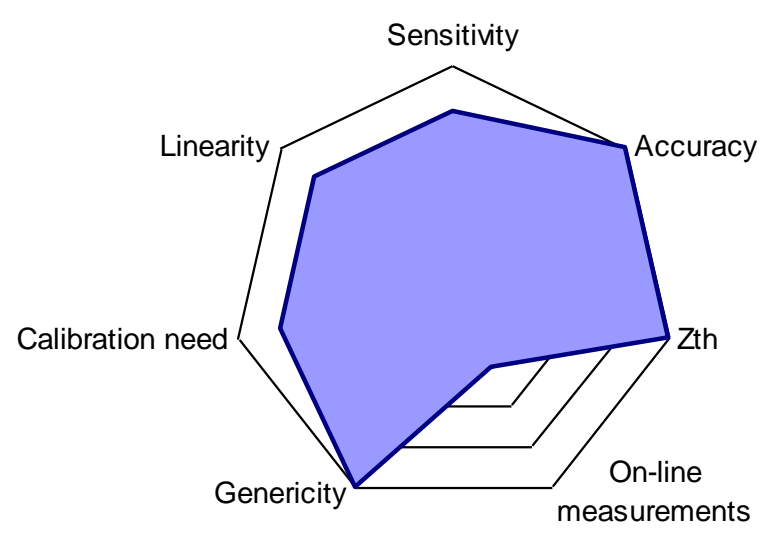

a. Voltage under a low current (diode, IGBT, MOSFET in off-state)

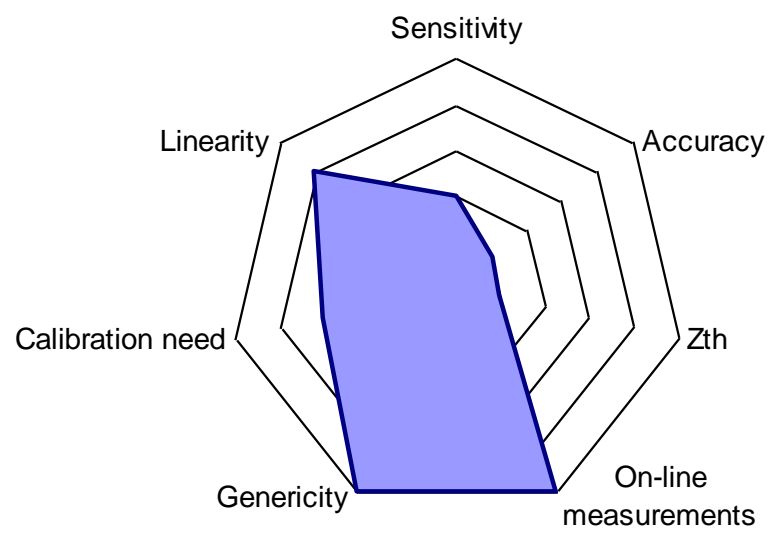

c. Voltage under a high current

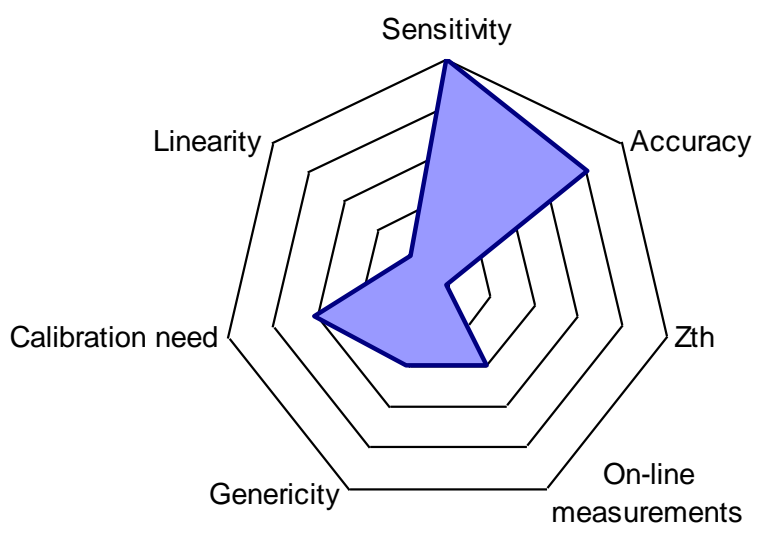

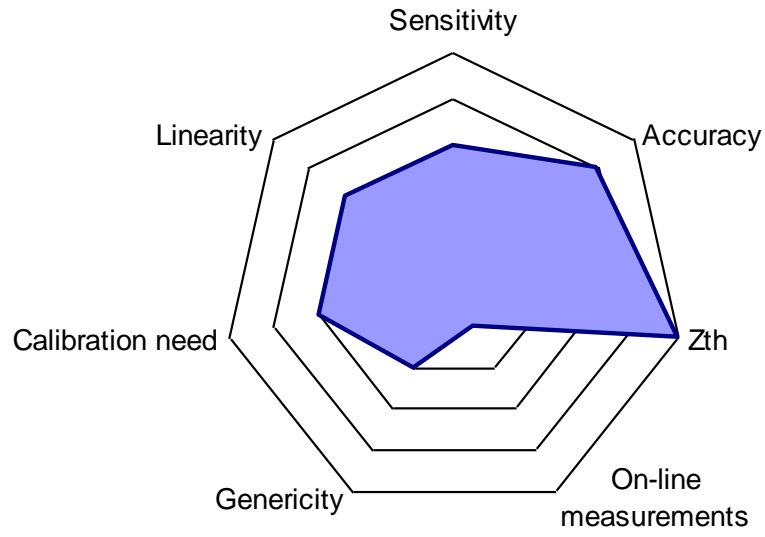

b. Threshold voltage

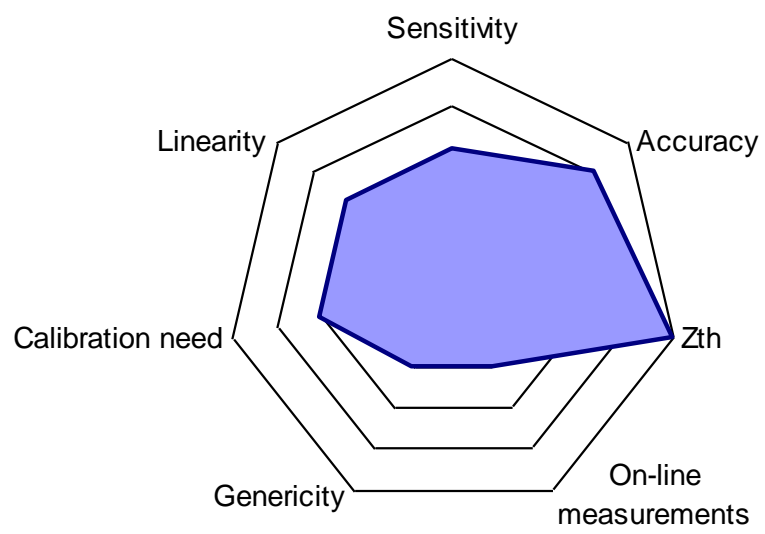

d. Gate-emitter voltage

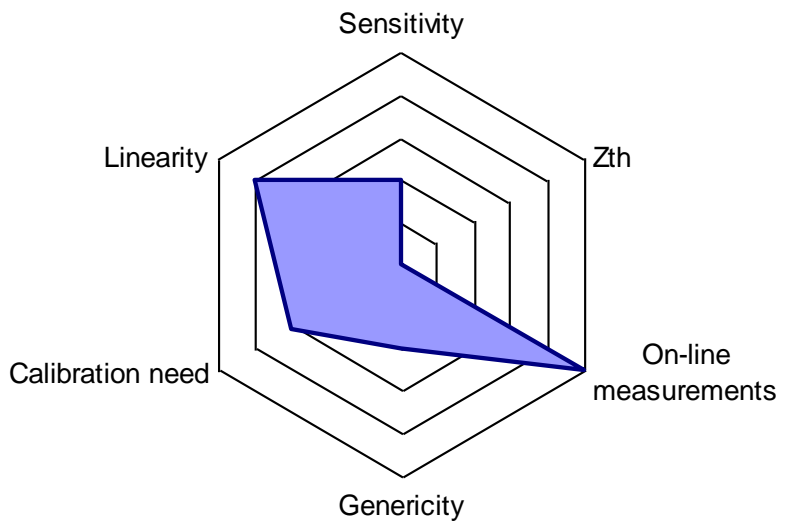


Fig. 15. Comparison of the different TSEPs

All presented TSEPs are well adapted for silicon power devices. Today, the use of wide band gap semiconductors like silicon carbide $(\mathrm{SiC})$ and gallium nitride $(\mathrm{GaN})$ is increasing due to their numerous advantages like the high switching frequency, the low on-state resistance, the high voltage rating and the high maximum junction temperature. The next paragraph presents the state of the art on the TSEPs of such power semiconductors.

\section{B. Wide band gap power devices}

1) About the calibration step

With wide band gap semiconductors, the calibration step is the same than this of silicon devices. But the potentiality of working under very high temperatures is a problem for the accuracy of the measurements. In fact the convective and radiative thermal losses are very large and it is difficult to know precisely the real temperature of the chip. This is the reason why authors like Borthen and Wachutka [57] present experimental setups in order to do precise characterizations of high temperature semiconductor devices. In [57] the experiment allows for measurements until $700^{\circ} \mathrm{C}$, a vacuum chamber is used in order to cancel the convective losses and to prevent the oxidation of the device.

2) About the switching times

The use of wide ban gap semiconductors allows for the reduction of the switching time [58-59]. For example, with HEMT GaN devices, the switching time can be only several tens of nanoseconds [59]. The use of the switching times as TSEP is thus not realistic at the moment.

\section{3) $\mathrm{SiC}$ devices}

The forward voltage of $\mathrm{SiC}$ devices varies with temperature [60-61]. Therefore it is possible to use the voltage under a low current or under a high current as TSEP. The saturation current and the threshold voltage also depend on the temperature [60], it is thus possible to use them as thermo-sensitive parameters as for silicon devices.

In the case of Schottky diodes, a possible TSEP is the voltage under a low current. It was used by Nowak et al. [33] but the authors do not give any value for the sensitivity of this parameter.

The JFET is the most studied device in term of TSEP. A first method is the measurement of the channel resistance in onstate [33, 62-64]. The sensitivity is about several $\mathrm{m} \Omega /{ }^{\circ} \mathrm{C}$ for devices having a channel resistance of several hundreds of $\mathrm{m} \Omega$. The sensitivity ratio $S$ is therefore very good but, as it has been said in case of silicon devices, the resistance of the electrical connections can be not negligible. Such measurements have to be made with caution in order to have accurate temperature 
measurements.

A second TSEP used by Bergogne et al. [64] is the measurement of the voltage of the body diode of the JFET under a low current, the JFET being in off-state. For the measurement of this TSEP, figure $6 \mathrm{c}$ can be used replacing the JFET by a MOSFET and maintaining the gate-source voltage in a negative value in the case of normally-on JFET. This TSEP is linear and the sensitivity is about $-2 \mathrm{mV} /{ }^{\circ} \mathrm{C}$. Moumen et al. and Ibrahim et al. [62-63] propose a third method. They use the forward voltage of the gate-source junction of the JFET (figure 16). The sensitivity is also about $-2 \mathrm{mV} /{ }^{\circ} \mathrm{C}$.
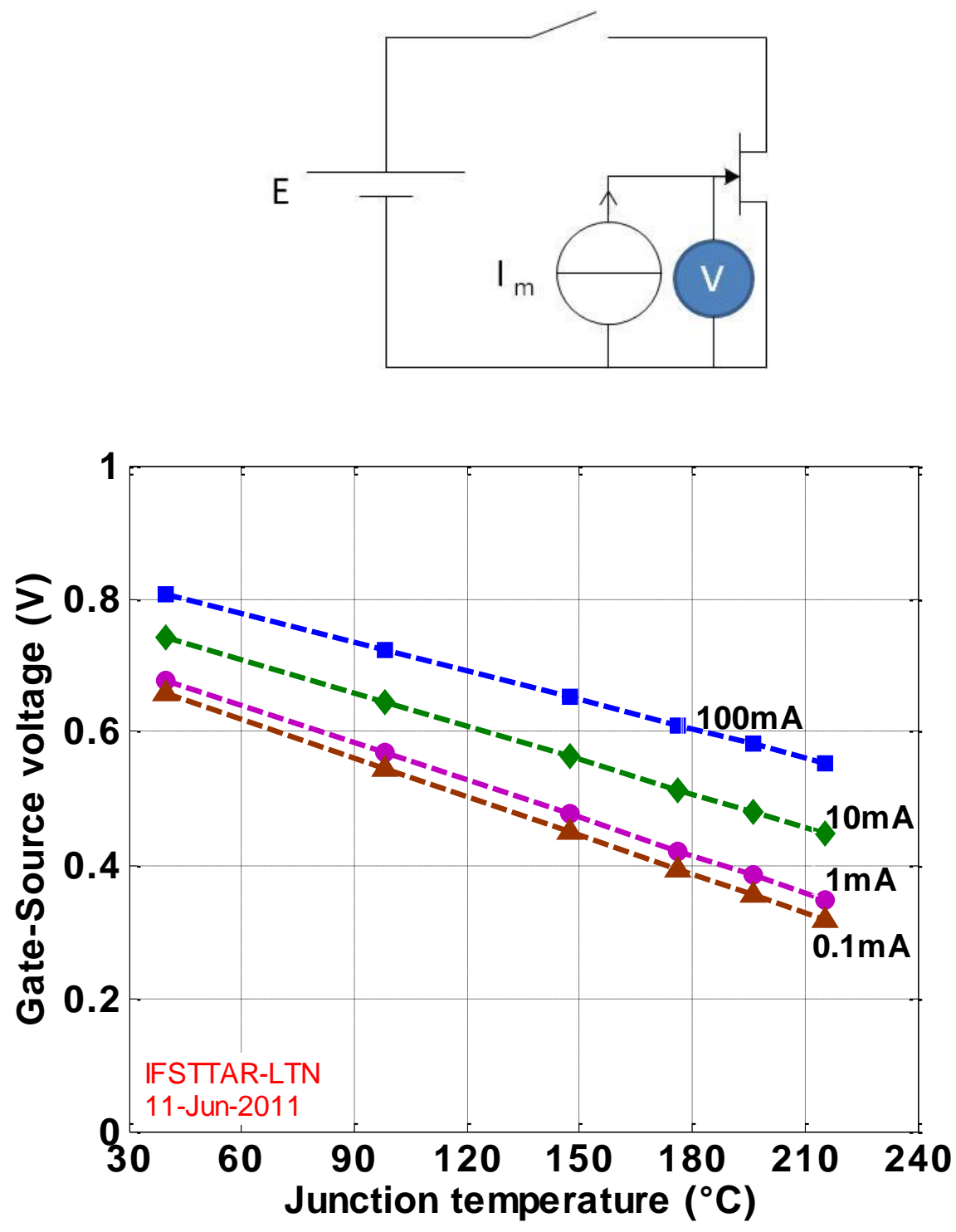

Fig. 16. Use of the gate-source junction of a JFET as TSEP

Nowak et al. [20] tried to use the saturation current in the case of SiC JFET. But they encountered some problems due to the low stability of the current. They explained that this was due to the dependence of this parameter on gate-source voltage, which has to be maintained as constant as possible. 


\section{4) $\mathrm{GaN}$ devices}

These devices are new, it is therefore very difficult to find papers dealing with their TSEPs. However Feng et al. [65] measure the chip temperature of a GaN HEMT using the forward voltage under a low current of the gate-source AlGaNGaN schottky diode. They obtain a sensitivity in the range -2 to $-3 \mathrm{mV} /{ }^{\circ} \mathrm{C}$.

\section{5) Conclusion}

At the moment, it is not possible to compare all TSEPs of wide band gap power devices because of the lack of data in the scientific literature. However, it seems preferable to choose at the moment a thermo-sensitive parameter inducing a voltage measurement on a Schottky or a PN junction under a low current. Indeed the measurements of gate-source voltage in active region or of the saturation current have not been yet performed and the measurement of channel voltages in on-state is possible but is hazardous.

\section{CONCLUSION}

In this paper the main methods used to estimate the chip temperature of semi-conductor power devices with ThermoSensitive Electrical Parameters (TSEP) have been presented and compared. An analysis of the different methods has been synthesized in the last section of this paper with a specific part dedicated to TSEPs of wide band gap components.

The voltage measurement under low currents seems to be most suitable TSEP for silicon and wide band gap components. Indeed, this solution is weakly sensitive to factors such as the electrical characteristics dispersion of a group of components with the same reference. In fact, this characteristic permits to reduce the experimental time duration of the calibration campaigns. In addition, the high-impedance status of the component with this measurement method limits the impact of the aging and the degradations of the electrical connections (principally the metallizations and the wire bonding).

Moreover, the presented TSEPs do not allow for a robust measurement of the chip temperature during a functional use. However improvements of chip temperature measurements with TSEPs in these conditions could be obtained in the future. Complementary works should be carried out in order to compare the chip temperature obtained with the TSEPs versus a referential chip temperature measurement solution using for example an infrared measurement or a thermo-reflectance system. Theoretical studies dealing with the physics of the semi-conductor components have also to be completed in order to increase the knowledge of TSEPs for silicon and wide band gap power devices. 


\section{REFERENCES}

[1] M.P. Rodriguez, N.Y.A. Shammas, A.T. Plumpton, D. Newcombe, D.E. Crees, "Static and dynamic finite element modelling of thermal fatigue effects in insulated gate bipolar transistor modules", Microelectronics Reliability, vol. 40, pp. 455-463, 2000.

[2] D-L. Blackburn, "Temperature measurements of semiconductor devices - a review", 20th Annual Semiconductor Thermal Measurement and Management Symposium, pp. 70-80, San Jose, CA, USA, March 11-24, 2004.

[3] L. Rossi, G. Breglio, A. Irace, P. Spirito, “Thermal Mapping of Power Devices with a Completely Automated Thermoreflectance Measurement System", Research in Microelectronics and Electronics Ph. D, 2006.

[4] C. Furbock, R. Thalhammer, M. Litzenberger, N. Seliger, D. Pogany, E. Gornik, G. Wachutka, “A differential backside laserprobing technique for the investigation of the lateral temperature distribution in power devices", The 11th International Symposium on Power Semiconductor Devices and ICs, pp. 193-196, Toronto, Ontario, Canada, May 26-28, 1999.

[5] R-K. Thalhammer, G. Wachutka, "Physically Rigorous Modeling of Internal Laser-Probing Techniques for Microstructured Semiconductor Devices", IEEE Transactions on Computed Aided Design of Integrated Circuits and Systems, vol. 23, pp. 60-70, 2004.

[6] D. Werber, G. Wachutka, "Interpretation of Laser Absorption Measurements on 4H-SiC Bipolar Diodes by Numerical Simulation", International Conference on Simulation of Semiconductor Processes and Devices, pp. 89-92, Hakone, Japan, Sept. 9-11, 2008.

[7] J. Zarebski, K. Gorecki, “The Electrothermal Large-Signal Model of Power MOS Transistors for SPICE”, IEEE Transactions on Power Electronics, vol.25, no.5, pp.1265-1274, 2010.

[8] P. Spirito, G. Breglio, V. d'Alessandro, N. Rinaldi, “Thermal instabilities in high current power MOS devices: experimental evidence, electrothermal simulations and analytical modeling”, 23rd International Conference on Microelectronics, pp. 23-30, Nis, Yugoslavia, May 12-15, 2002.

[9] G. Breglio, A. Irace, P. Spirito, R. Letor, S. Russo, "Fast transient infrared thermal analysis of smart Power MOSFETS in permanent short circuit operation”, 18th International Symposium on Power Semiconductor Devices \& IC's, pp. 1-4, Naples, Italy, June 4-8, 2006.

[10] U. Scheuermann, S. Schuler, "Power cycling results for different control strategies”, Microelectronics Reliability, vol. 50, pp. 1203-1209, 2010.

[11] W. Brekel, T. Duetemeyer, G. Puk, O. Schilling, "Time resolved in situ Tvj measurements of 6.5kV IGBTs during inverter operation”, Proceedings PCIM Europe, pp. 806-813, Nuremberg, Germany, May 12-14, 2009.

[12] S. Carubelli, Z. Khatir, "Experimental validation of a thermal modelling method dedicated to multichip power modules in operating conditions", Microelectronics Journal, vol. 34, pp. 1143-1151, 2003.

[13] A. Hamidi, G. Coquery, R. Lallemand, P. Vales, J.M. Dorkel, “Temperature measurements and thermal modeling of high power IGBT multichip modules for reliability investigations in traction applications", Microelectronics Reliability, vol. 38, pp. 1353-1359, 1998.

[14] L-M. Hillkirk, B. Breitholtz, M. Domeij, "Space and time resolved surface temperature distributions in Si power diodes operating under selfheating conditions", Solid-State Electronics, vol. 45, pp. 2057-2067, 2001.

[15] L-M. Hillkirk, "Dynamic surface temperature measurements in SiC epitaxial power diodes performed under single-pulse self-heating conditions", Solid-State Electronics, vol. 48, pp. 2181-2189, 2004.

[16] M. Riccio, A. Irace, G. Breglio, P. Spirito, V. Kosel, M. Glavanovics, A. Satka, "Thermal simulation and ultrafast IR temperature mapping of a Smart Power Switch for automotive applications”, 21st International Symposium on Power Semiconductor Devices \& IC's, pp. 200-203, Barcelona, Spain, June 14-18, 2009. 
[17] M. Riccio, A. Irace, G. Breglio, P. Spirito, E. Napoli, Y. Mizuno, "Electro-thermal instability in multi-cellular Trench-IGBTs in avalanche condition: experiments and simulations”, 23rd International Symposium on Power Semiconductor Devices \& IC's, pp. 1-4, San Diego, CA, USA, May 23-26, 2011.

[18] T. Hashimoto, T. Kawashima, T. Uno, N. Akiyama, N. Matsuura, H. Akagi, “A System-in-Package (SiP) With Mounted Input Capacitors for Reduced Parasitic Inductances in a Voltage Regulator”, IEEE Transactions on Power Electronics, vol.25, no.3, pp.731-740, 2010.

[19] Y. Avenas, L. Dupont, "Comparison of junction temperature evaluations in a power IGBTs module using an IR camera and three thermo-sensitive electrical parameters", The Applied Power Electronics Conference and Exposition, Orlando, Florida, USA, Feb. 5-9, 2012.

[20] T. Brückner, S. Bernet, "Estimation and measurement of junction temperatures in a three-level voltage source converter", IEEE Transactions on Power Electronics, vol. 22, pp. 3-12, 2007.

[21] C-S. Yun, P. Reglil, J. Waldmeyer, W. Fichtner, "Static and dynamic thermal characteristics of IGBT power modules", 11th International Symposium on Power Semiconductor Devices and ICs, pp. 37-40, Toronto, Ont., Canada, May 26-28, 1999.

[22] M. Mermet-Guyennet, X. Perpina, M. Piton, "Revisiting power cycling test for better life-time prediction in traction", Microelectronics Reliability, vol. 47, pp. 1690-1695, 2007.

[23] R. Schmidt, U. Scheuermann, "Using the chip as a temperature sensor - The influence of steep lateral temperature gradients on the Vce(T)measurement", 13th European Conference on Power Electronics and Applications, pp. 1-9, Barcelona, Spain, Sept. 8-10, 2009.

[24] A. Hamidi, G. Coquery, "Effects of current density and chip temperature distribution on lifetime of high power IGBT modules in traction working conditions", Microelectronics Reliability, vol. 37, pp. 1755-1758, 1997.

[25] D. Bin; J-L. Hudgins, E. Santi, A-T. Bryant, P-R. Palmer, H-A. Mantooth, "Transient Electrothermal Simulation of Power Semiconductor Devices, IEEE Transactions on”, IEEE Transactions on Power Electronics, vol.25, no.1, pp.237-248, 2010.

[26] F. Volle, S-V. Garimella, M-A. Juds, "Thermal Management of a Soft Starter: Transient Thermal Impedance Model and Performance Enhancements Using Phase Change Materials”, IEEE Transactions on Power Electronics, vol.25, no.6, pp.1395-1405, 2010.

[27] G.B.M. Fiege, F.-J. Niedernostheide, H.-J. Schulze, R. Barthelmeg, L.J. Balk, "Thermal characterization of power devices by scanning thermal microscopy techniques", Microelectronics Reliability, vol. 39, pp. 1149-1152, 1999.

[28] D-L. Blackburn, "An electrical technique for the measurement of the peak junction temperature of power transistors", 13th Annual Reliability Physics Symposium, pp. 143-150, Las Vegas, Nevada, USA, April 1-3, 1975.

[29] E. Farjah, R. Perret, “Application and analysis of thermosensitive parameters in the case of hybrid power modules”, IEEE Industry Applications Society Annual Meeting, , pp. 1284-1289, Orlando, Florida, USA, Oct. 8-12, 1994.

[30] D-L. Blackburn, "A review of thermal characterization of power transistors", Fourth Annual IEEE Semiconductor Thermal and Temperature Measurement Symposium, pp. 1-7, San Diego, CA, USA, Feb. 10-12, 1988.

[31] J-W. Sofia, "Electrical measurement using semiconductors", Electronics Cooling, Vol. 3, pp. 22-25, 1997.

[32] Z. Khatir, L. Dupont, A. Ibrahim, "Investigations on junction temperature estimation based on junction voltage measurements", Microelectronics Reliability, vol. 50, pp. 1506-1510, 2010.

[33] M. Nowak, J. Rabkowski, R. Barlik, "Measurement of temperature sensitive parameter characteristics of semiconductor silicon and siliconcarbide power devices", 13th Power Electronics and Motion Control Conference, pp. 84-87, Poznan, Poland, Sept 1-3, 2008. 
[34] M. Musallam, C-M. Johnson, "Real-Time Compact Thermal Models for Health Management of Power Electronics", IEEE Transactions on Power Electronics, vol.25, no.6, pp.1416-1425, 2010.

[35] C-M. Barnes, P-E. Tuma, "Practical Considerations Relating to Immersion Cooling of Power Electronics in Traction Systems", IEEE Transactions on Power Electronics, vol.25, no.9, pp.2478-2485, 2010.

[36] D-L. Blackburn, D-W. Berning, "Power MOSFET temperature measurements", Annual Power Electronics Specialists Conference, pp. 400-407, Cambridge, Massachussets, USA, June 14-17, 1982.

[37] A. Ammous, B. Allard, H. Morel, “Transient temperature measurements and modeling of IGBT’s under short circuit”, IEEE Transactions on Power Electronics, vol. 13, no 1, pp. 12-25, 1998.

[38] P. Cova, M. Ciappa, G. Franceschini, P. Malberti, F. Fantini, “Thermal characterization of IGBT power modules”, Microelectronics Reliability, vol. 37, no 10/11, pp. 1731-1734, 1997.

[39] S. Duong, S. Rael, C. Schaeffer, J.F. De Palma, "Short circuit behaviour for PT and NPT IGBT devices - protection against explosion of the case by fuse", European Conference on Power Electronics and Applications, pp. 249-254, Seville, Spain, Sept. 19-21, 1995.

[40] L. Meysenc, L. Saludjian, A. Bricard, S. Rael, C. Schaeffer, “A high heat flux IGBT micro exchanger setup”, IEEE Transactions on Components, Packaging, and Manufacturing Technology, Part A, vol. 20, pp. 334-341, 1997.

[41] Z. Jakopovic, Z. Bencic, F. Kolonic, "Important properties of transient thermal impedance for MOS-gated power semiconductors", IEEE International Symposium on Industrial Electronics, pp. 574-578, Bled, Slovenia, July 12-16, 1999.

[42] H. Chen, V. Pickert, D.J. Atkinson, L.S. Pritchard, "On-line monitoring of the MOSFET device junction temperature by computation of the threshold voltage", The 3rd IET International Conference on Power Electronics, Machines and Drives, pp. 440-444, Dublin, Ireland, Apr. 4-6, 2006.

[43] X. Cao, T. Wang, G-Q. Lu, K.D.T. Ngo, "Characterization of lead-free solder and sintered nano-silver die-attach layers using thermal impedance", International Power Electronics Conference, pp. 546-552, Sapporo, Japan, June 21-24, 2010.

[44] X : Y. Huang, C. Lü, X. Xie, Y. Fan, J. Zhang, X. Meng, “A Study of Test System for Thermal Resistance of IGBT”, 2010 Asia Pacific Conference on Postgraduate Research in Microelectronics and Electronics (PrimeAsia), pp. 312-315, Shangai, China, Sept. 22-24, 2010.

[45] A. Koenig, T. Plum, P. Fidler, R-W. De Doncker, "On-line junction temperature measurement of CoolMOS devices", 7th International Conference on Power Electronics and Drive Systems, pp. 90-95, 2007.

[46] Y-S. Kim, S-K. Sul, "On-line estimation of IGBT junction temperature using on-state voltage drop", The 1998 IEEE Industry Applications Conference, pp. 853-859, St Louis, Missouri, USA, Oct. 12-15, 1998.

[47] X. Perpiñà, J. F. Serviere, J. Saiz, D. Barlini, M. Mermet-Guyennet, J. Millán, “Temperature measurement on series resistance and devices in power packs based on on-state voltage drop monitoring at high current”, Microelectronics Reliability, vol. 46, pp. 1834-1839, 2006.

[48] D. Berning, J. Reichl, A. Hefner, M. Hernandez, C. Ellenwood, J-S. Lai, "High speed IGBT module transient thermal response measurements for model validation”, 38th IAS Annual Meeting Industry Applications Conference, pp. 1826-1832, Salt Lake City, Utah, USA, Oct. 12-16, 2003.

[49] M. Ayadi, M. A. Fakhfakh, M. Ghariani, R. Neji, "Electro-thermal simulation of a three phase inverter with cooling system", Journal of Modelling and Simulation of Systems, vol. 1, pp. 163-170, 2010.

[50] D. Bergogne, B. Allard, H. Morel, "An estimation method of the channel temperature of power MOS devices", IEEE 31st Annual Power Electronics Specialists Conference, pp. 1594-1599, Galway, Ireland, June 18-23, 2000. 
[51] A. Castellazzi, G. Wachutka, "Low-voltage PowerMOSFETs used as dissipative elements: electrothermal analysis and characterization", 37th IEEE Power Electronics Specialists Conference, pp. 1-7, Jeju, Korea, June 18-22, 2006.

[52] D. Barlini, M. Ciappa, M. Mermet-Guyennet, W. Fichtner, "Measurement of the transient junction temperature in MOSFET devices under operating conditions", Microelectronics Reliability, vol. 47, pp. 1707-1712, 2007.

[53] H. Kuhn, A. Mertens, "On-line junction temperature measurement of IGBTs based on temperature sensitive electrical parameters", 13th European Conference on Power Electronics and Applications, pp. 1-10, Barcelona, Spain, Sept. 8-10, 2009.

[54] D. Barlini, M. Ciappa, A. Castellazzi, M. Mermet-Guyennet, W. Fichtner, "New technique for the measurement of the static and of the transient junction temperature in IGBT devices under operating conditions”, Microelectronics Reliability, vol. 46, pp. 1772-1777, 2006.

[55] V. Smeth, "Aging and failure modes of IGBT power modules undergoing power cycling in high temperature environments", PhD Thesis, Montpellier 2 University, France, 2010.

[56] Z. Arbanas, "High power density 1 MW motor inverter", IEEE International Electric Machines and Drives Conference Record, pp WB1-2.1WB1-2.2, Sao Paulo, Brazil, May 18-21, 1997.

[57] P. Borthen, G. Wachutka, "Characterization of Semiconductor Devices at Very High Temperatures", ASDAM 2008, The Seventh International Conference on Advanced Semiconductor Devices and Microsystems, pp. 71-74, Smolenice Castle, Slovakia, Oct. 12-16, 2008.

[58] A. Knop, W-T. Franke, F-W. Fuchs, "Switching and conducting performance of SiC-JFET and ESBT against MOSFET and IGBT", 13th Power Electronics and Motion Control Conference, pp. 69-75, Poznan, Poland, Sept 1-3, 2008.

[59] M. Danilovic, Z. Chen, R. Wang, F. Luo, D. Boroyevich, P. Mattavelli, "Evaluation of the Switching Characteristics of a Gallium-Nitride Transistor", IEEE Energy Conversion Congress \& Exposition, pp. 2681-2688, Phoenix, Arizona, USA, Sept. 17-22, 2011.

[60] B. Wrzecionko, J. Biela, J-W. Kolar, "SiC power semiconductors in HEVs: Influence of junction temperature on power density, chip utilization and efficiency", 35th Annual Conference of IEEE Industrial Electronics, pp. 3834-3841, Porto, Portugal, Nov. 3-5, 2009.

[61] J. Luo; K-J. Chung; H. Huang; J-B. Bernstein, “Temperature dependence of Ron,sp in silicon carbide and GaAs Schottky diode”, 40th Annual Reliability Physics Symposium, pp. 425-426, Dallas, Texas, USA, April 7-11, 2002.

[62] S. Moumen, S. Lefebvre, Z. Khatir, J-C. Faugières, "Indirect thermal measurement on SIC JFET transistors", 13th European Conference on Power Electronics and Applications, pp. 1-10, Barcelona, Spain, Sept. 8-10, 2009.

[63] A. Ibrahim, Z. Khatir, L. Dupont, "Characterization and aging test methodology for power electronic devices at high temperature", Advanced Materials Research, vol. 324, pp. 411-414, 2011.

[64] D. Bergogne, A. Hammoud, D. Tournier, C. Buttay, Y. Amieh, P. Bevilacqua, A. Zaoui, H. Morel, B. Allard, "Electro-thermal behaviour of a SiC JFET stressed by lightning-induced overvoltages", 13th European Conference on Power Electronics and Applications, pp. 1-8, Barcelona, Spain, Sept. 8-10, 2009.

[65] S. Feng, P. Hu, G. Zhang, C. Guo, X. Xie, T. Chen, "Determination of channel temperature of AlGaN/GaN HEMT by electrical method", 26th Annual IEEE Semiconductor Thermal Measurement and Management Symposium, pp. 165-169, Santa Clara, CA, USA, Feb. 21-25, 2010. 